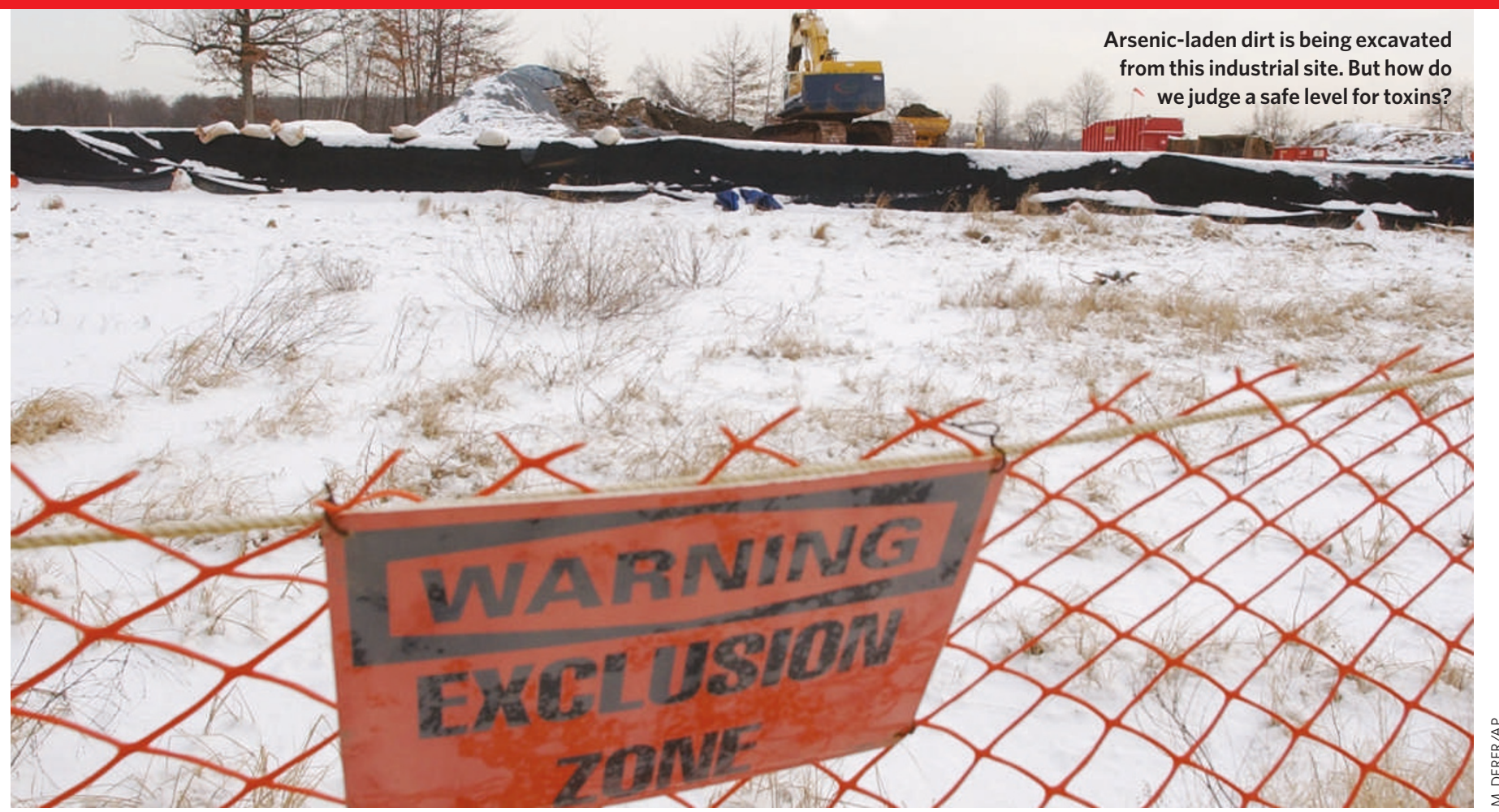

\title{
Safe and sound?
}

\section{The White House is trying to reform environmental and health regulation across the board. But it is doing so very quietly. Colin Macilwain takes a look behind the scenes.}

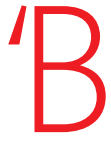
ush declares war on environment,' read an unflattering CNN headline in March 2001. It was early in the administration of President George W. Bush, and the White House had just upwardly revised how much arsenic it would allow in drinking water. Never mind that they had stepped into a trap laid by former president Bill Clinton, who sharply lowered the acceptable level of arsenic just before leaving office. The direct approach to changing the standards didn't play well, and it would be the last time the administration openly sought to relax a pollution rule.

After that, the usually direct administration took a discreet approach to reforming the way in which the US federal agencies regulate everything from drinking-water standards and air quality to airport security and work safety. The approach is so discreet that few outside Washington DC even realize it exists. Its headquarters are at the Office of Information and Regulatory Affairs, at the White House Office of Management and Budget (OMB) - the lowkey powerhouse that oversees the $\$ 2.7$-trillion annual spending of the federal government.

Until this February, the effort's chief engineer was John Graham, a soft-spoken, bespectacled former director of the Center for Risk Analysis at Harvard. When Graham quit the government to run the Pardee RAND sciencepolicy graduate school in Santa Monica, California, he left behind a proposal that could radically change how health, safety and environmental rules are drawn up. Its real effect would be to relax them, critics charge.

The OMB Bulletin on Risk Assessment landed quietly on agency officials' desks in January. The 26-page document outlines proposed changes to the way the government conducts risk assessments - the scientific studies that quantify the risks to human health, safety and the environment caused by various activities. The bulletin is merely a proposal at

\section{"They greeted my proposal with a long silence and a blank stare, as if risk assessment was a term from a foreign language" - John Graham}

this stage and, unusually, the OMB has sent it to the National Academies for review. An academies panel chaired by John Ahearne, an engineer and former head of the Nuclear Regulatory Commission now at Duke University in Durham, North Carolina, will report on it in November. The OMB should issue its final bulletin soon afterwards. And all federal agencies will be expected to adhere to it.

"The quality of risk assessment in the federal government is uneven," explains Graham. "What we're trying to attain is a standard across the government."
But already the knives are out for the proposal. Environmental and consumer groups charge that its real aim is to weaken regulators, such as the Environmental Protection Agency (EPA) and the Food and Drug Administration. "If this is adopted in anything close to its current form," says Rena Steinzor, a regulatoryaffairs specialist at the University of Maryland in Baltimore, "it will have a devastating impact on public health and safety regulations."

Congress is also getting involved. On 5 May, leading Democrats in the House of Representatives fired off a letter to the president of the National Academy of Sciences, Ralph Cicerone. In it, Tennessee's Bart Gordon, Michigan's John Dingell and other senior Democrats ask the National Academies to spell out the limitations of its own review. In effect, they warn it to refrain from filing a scientific endorsement of what they regard as a fundamentally political proposal.

"It appears impossible to provide a comprehensive answer to the questions without reaching beyond the scope of a scientific review," says the letter. It goes on to charge that the "OMB's proposed bulletin is in conflict with the approach taken in existing law" - which, the authors say, already instructs individual agencies on how to assess particular risks.

Both supporters and critics agree that the document is the crowning achievement of Graham's long march to regulatory reform. It is the fourth important element that he put in place 
from his powerful position at the OMB. Three broad-ranging edicts on how agencies should, and should not, go about the production of regulations have already been issued: they covered 'information quality', cost-benefit analyses and scientific peer review. The last drew a sharp and uninvited riposte from the National Academies when it was released in 2003. The academies said it was far too prescriptive in telling scientists how to review the work of their peers; the document was subsequently watered down to accommodate the concerns.

The main scope of January's risk-assessment bulletin is twofold: it offers guidance on how government agencies should go about conducting such assessments, and broadens the set of circumstances in which they need to be done.

Scientific risk assessments are murky affairs at the best of times. The US environmental movement, in its 1970s heyday, strongly resisted the very concept; greens prefer the rival paradigm of the 'precautionary principle'. This principle holds that a regulator responsible for, say, clean water, should respond to uncertainty about the toxic effects of a given chemical by setting a limit that it holds to be safe, in advance of more precise information. The approach is anathema to regulated industries, but it has been embraced, at least in theory, by political leaders in the European Union. By contrast, in the United States, where water and air quality are more tightly regulated, risk assessment has been incorporated into many environmental laws. With the bulletin, it would be officially incorporated into all federal-agency responses to risk.

\section{Triple bill}

Graham has cited three main examples in support of the need for the bulletin. One takes issue with a $2002 \mathrm{EPA}$ estimate of the 'safe' dose in drinking water of perchlorate - an ingredient in solid rocket fuel, often dumped on public land by the Department of Defense. A subsequent, 2005 National Academies study identified a much higher safe dose of the chemical than the EPA had done - leading the agency's critics to say that it should take more care before issuing such dose estimates.

The second case also concerns the EPA, and an estimate that it made of deaths caused from cardiopulmonary disease as a result of diesel fuel emissions from off-road vehicles. The EPA made its estimate, Graham argues, even as it requested millions of dollars to research the topic. It turned out that the agency's estimate was merely a central value between risks that might be much higher or much lower, depending on the outcome of the research. "When an agency produces a risk assessment with false precision," says Graham, "it engenders negative reactions from stakeholders and from the scientific community."

His third example addresses a rather different area. The Department of Agriculture decided to shut the Canadian border to cattle

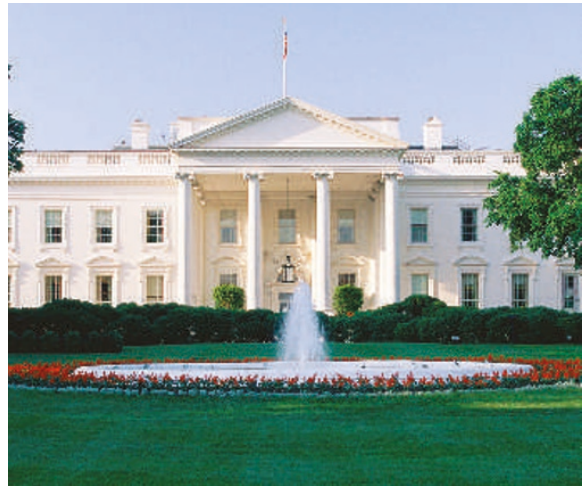

under the new rules, she claims.

The measures enacted by the OMB, critics say, will provide enough sawdust to clog up the wheels of government regulation for years to come. "The aim is to bog the process down, in the name of transparency," says Robert Shull, head of regulatory policy at the pressure group OMB Watch, based in Washington DC.

Graham, a former economist, says its aim is quite the opposite. "There will be some cases where risk assessments will become more expensive" as a result of the bulletin, he concedes. "But their improved quality will mean less controversy and less delay — so we can see

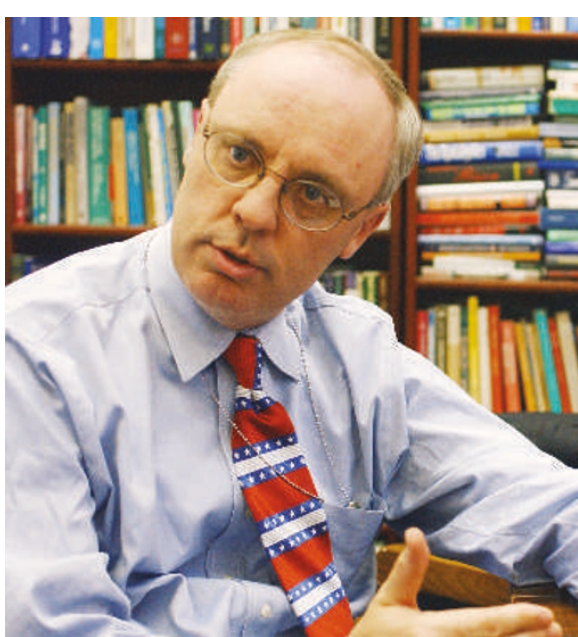

Main man: John Graham has led the White House mission to change agencies' approach to risk.

trading after mad cow disease was found in Canadian cattle in May 2003. Graham says that when he raised the issue of a risk assessment with department officials, as they were considering re-opening the border, he got "a long silence and a blank stare, as if risk assessment was a term from a foreign language".

Only last week, a National Academies panel took sharp issue with yet another EPA risk assessment - a 2003 estimate of the cancer risk posed by chemicals called dioxins. The panel, chaired by David Eaton of the University of Washington in Seattle, said that the agency had failed to quantify the risks in its assessment, or to justify the main assumptions behind it.

Graham's bulletin would require government decisions to be subjected to formal risk assessment; in emergencies, this could be completed after the decision was implemented. Deciding what constitutes an emergency can be difficult, however, and critics claim the regime would stifle government action. "They won't be able to react to things that involve a rapid decision," says Jennifer Sass of the Natural Resources Defense Council, an environmental group based in New York. For instance, the EPA moved swiftly to monitor mould growth in New Orleans after Hurricane Katrina - a response that might not be possible opportunities for saving time and money."

\section{Fans in commerce}

The measure's strongest supporters are the US Chamber of Commerce and industry groups such as the American Chemistry Council, headquartered in Arlington, Virginia. "It crystallizes 15 to 20 years of research on how best to do risk assessment, on the basis of what has been said by the National Academies and others," says the chemistry council's senior toxicologist, Richard Becker. His group has endorsed the proposal and suggests that it be given more teeth by making it subject to judicial review, in which an aggrieved party can challenge the government's implementation of it.

The National Academies is accustomed to being in the middle of this kind of fight, but it is rarely asked to review a policy proposal before it goes into force. Sceptics smell a trap: the academies' unsolicited intervention greatly diluted the previous White House proposal on standardizing peer review of scientific evidence. By asking for its advice first, the OMB can hope to implement a final rule - which it will write itself - that will be difficult for future administrations to overturn.

The only time the unflappable Graham looks ruffled is when asked if his sending of the proposed bulletin to the academies for endorsement might be regarded as a ploy to muffle political criticism. "Anyone who believes that the National Academies can be used in that way doesn't understand the process," he sniffs. "Perhaps the OMB should be given credit for allowing its work to be criticized by the scientific community. There was no legal requirement for it to do so."

Whatever the National Academies says in November, a rule is likely to be implemented that will embed risk assessment more deeply in the decision-making process. This will be John Graham's permanent legacy, subtly moving the regulatory goalposts in industry's favour, without catching the public's eye. "It all sounds very nice and sensible," says Shull. "Politically, it is much more viable than, say, trying to weaken the drinking-water standards."

Colin Macilwain writes for Nature from Edinburgh. 